\title{
Anesthesia for Lung Lavage in Pediatric Patient with Pulmonary Alveolar Proteinosis
}

\author{
Breno Monteiro Gonçalves, TEA 1, Vera Coelho Teixeira, TSA ², Paulo Fernando Souto Bittencourt ${ }^{3}$
}

\begin{abstract}
Summary: Gonçalves BM, Teixeira VC, Bittencourt PFS - Anesthesia for Lung Lavage in Pediatric Patients with Pulmonary Alveolar Proteinosis.

Background and objectives: Pulmonary Alveolar Proteinosis (PAP) is a rare disorder first described in 1958. The Whole-Lung Lavage (WLL) proposed in the $1960 \mathrm{~s}$, remains the treatment of choice. Several techniques have been described to perform lung lavage in pediatric patients; however, all have limitation and risks.

Case report: Female patient, aged 6 years and 8 months, $25 \mathrm{~kg}$, diagnosed with pulmonary alveolar proteinoisis, who underwent whole-lung lavage by sequential lobar fiberoptic bronchoscopy under general anesthesia and spontaneous ventilation.
\end{abstract}

Keywords: Anesthesia, Inhalation; Bronchoscopy; Pediatrics; Pulmonary Alveolar Proteinosis; Ventilation.

(C2012 Elsevier Editora Ltda. All rights reserved.

\section{INTRODUCTION}

Pulmonary Alveolar Proteinosis (PAP) is a rare disorder first described in 1958 and characterized by alveolar filling with a lipoprotein non-cellular material positive for periodic acidSchiff ${ }^{1}$. Prevalence of PAP is 3.7 cases per million people ${ }^{2}$. Most patients are men (male-female ratio of 2,65:1) and smokers $(72 \%)^{3}$.

PAP includes three distinct classes of disease (acquired, congenital and secondary) with a similar spectrum of histopathological findings. Acquired PAP, which is responsible for more than $90 \%$ of cases, presents itself with a gradual onset of progressive dyspnea associated with a cough and less frequently with fever, chest pain and hemoptysis ${ }^{4}$.

Proposed in the 1960 s by Ramirez et al. ${ }^{5,6}$ Whole-Lung Lavage (WLL) is still the treatment of choice, providing an increase in $\mathrm{PaO}_{2}$, improved pulmonary function (FEV1, VC and diffusing capacity for carbon monoxide) and an increase in 5 -year survival ${ }^{3}$.

\section{Received from Hospital Felício Rocho, Brazil.}

1. Anesthesiologist; Hospital Felicio Rocho.

2. Diplomat in Intensive Care; Diploma in Internal Medicine; Anesthesiologist, Hospital Felicio Rocho.

3. MSc; PhD; Universidade Federal de Minas Gerais (UFMG); Diploma in Endoscopy; Physician, Hospital Felicio Rocho, Instituto Alfa do Hospital das Clínicas da UFMG, Hospital Infantil João Paulo II, and Hospital de Pronto-Socorro João XXIII.

Submitted on April 26, 2011.

Approved on June 19, 2011.

Correspondence to:

Dr. Breno Monteiro Gonçalves

Rua Lauro Ferreira, 101, Bloco 2, APT 801

Buritis

30575080 - Belo Horizonte, MG, Brazil

E-mail: breno83@hotmail.com
In pediatric patients the WLL with a Double-Lumen Endotracheal Tube (DLET) is not possible due to the reduced caliber of the airways of these patients. Several techniques have been described to perform lung lavage in pediatric patients; however, all present limitations and risks ${ }^{7-12}$.

This report describes the WLL by sequential lobar fiberoptic bronchoscopy in a pediatric patient under general anesthesia and spontaneous ventilation.

\section{CASE REPORT}

Female patient, aged 6 years and 8 months, $25 \mathrm{~kg}$ with dyspnea on exertion and tachydyspnea for two months, evolving into fever, chest pain and worsening on pulmonary auscultation over the past three days, was referred to the Hospital Felício Rocho for examination due to clinical worsening.

On admission the patient was in good general condition, ruddy, hydrated, with moderate tachydyspnea, diffusely decreased breath sounds with crackles and bronchophony in the left hemithorax and receiving 2 L. min $^{-1}$ of oxygen through a nasal cannula and cefuroxime (D1).

Chest X-ray showing diffuse bilateral alveolar-interstitial infiltrates; chest tomography with thickening of the interlobular septa; consolidations and ground-glass opacity. Arterial blood gas analysis: receiving 2 L.min-1 oxygen by nasal cannula; $\mathrm{pH}$ of $7.36 ; \mathrm{pCO}_{2} 30 \mathrm{mmHg} ; \mathrm{pO}_{2}$ of $82 \mathrm{mmHg} ; \mathrm{HCO}^{-3}$ of $16.8 \mathrm{mmol}^{-L^{-1}}$; hemoglobin of $16.4 \mathrm{~g}^{\mathrm{dL}}{ }^{-1}$; hematocrit of $48 \%$; 7,000 leukocytes. $\mathrm{mm}^{-3}$ and 177,000 platelet. $\mathrm{mm}^{-3}$; PCR of $48 \mathrm{mg} \mathrm{L}^{-1}$; and LDH of 527 U.L-1.

Antibiotic therapy was changed to cefotaxime completing 10 days of treatment. The patient was uneventful, with improvement in tachydyspnea and pulmonary auscultation normalized, but remained dependent on oxygen via nasal cannula. 
A new chest tomography showed a pattern similar to the previous examination (thickening of the interlobular septa and ground-glass opacity). Bronchoscopy with Bronchoalveolar Lavage (BAL) showed that the larynx, trachea, and bronchi were endoscopically normal. Anatomopathological examination of BAL fluid showed a large amount of amorphous material stained by PAS compatible with a diagnosis of pulmonary alveolar proteinosis. BAL findings were negative for fungi, Gram, culture, AFB, Pneumocystis carinii, and PCR for Mycobacterium tuberculosis.

WLL was then indicated and performed by sequential lobar fiberoptic bronchoscopy with the patient under general anesthesia. Inhalation induction was performed with sevoflurane, venous puncture in the left upper limb with $22 \mathrm{G}$ Jelco and endotracheal intubation tube with cuff number $3.5 \mathrm{~mm}$.

During the procedure monitoring was performed with ECG monitors, noninvasive blood pressure, pulse oximetry, capnography, inspired oxygen fraction and gas analyzer.

The patient was kept under spontaneous ventilation with $100 \% \mathrm{O}_{2}$ with sevoflurane expired fraction ranging between 1 and 1.5 MAC. Fiber bronchoscope Olympus BF-3C10 with a diameter of $4.9 \mathrm{~mm}$ was introduced adjacent to the endotracheal tube until impaction in the left upper lobe bronchus.

After impaction lavage of the left upper lobe was performed with warm saline solution. Then the fiber bronchoscope was impacted in the left lower bronchus and the procedure was repeated. Approximately $800 \mathrm{~mL}$ of $0.9 \%$ saline solution was used for the WLL and the effluent had a milk-like appearance. The patient remained hemodynamically stable throughout the procedure without severe hypoxemia and pulse oximetry always over $90 \%$. She was transferred to the ICU after the procedure and extubated a few minutes after admission. The patient remained on oxygen via nasal cannula for less than 24 hours and was discharged to the room the next day in ambient air. The chest X-ray performed in the ICU showed improvement of alveolarinterstitial infiltrates in the left lung.

The patient was discharged 48 hours after the procedure. Right lung lavage was performed without complications eight days after the first procedure under the same anesthetic technique with $1.100 \mathrm{~mL}$ of $0.9 \%$ saline solution. However, the patient was extubated in the operating room and did not require oxygen therapy during the ICU stay. The patient was discharged 24 hours after lavage with complete remission of symptoms associated with pulmonary alveolar proteinosis to continue treatment in her hometown.

\section{DISCUSSION}

WLL remains the treatment of choice for PAP and is a safe procedure that provides lasting benefits with more than $70 \%$ of patients free of recurrence for seven years ${ }^{13-18}$.
Currently the WLL technique with a double-lumen tube and lung isolation is well established for adult patients $3,4,13-19$. However, pediatric patients present a technical challenge for WLL due to the absence of DLET compatible with the airway caliber of these patients ${ }^{20-23}$.

There are reports in literature about some alternatives for WLL performance in pediatric patients ${ }^{7-12}$. The usage of total and partial cardiopulmonary bypass for blood oxygenation during lung lavage was reported with success, despite the aggregate cost, complexity and morbidity of the procedure $7,21,24$.

The selective intubation of the main bronchi, as well as the introduction of a fiber bronchoscope inside a tracheal tube were also described to perform WLL in pediatric patients ${ }^{9,22,23}$. However, the major limitation of both techniques is the airway diameter compared to the diameter of the bronchoscope and the tracheal tube, in addition to the risk of trauma and stenosis.

Moazam et al. ${ }^{9}$ described the performance of a successfully WLL in an infant (15 weeks old, $2 \mathrm{~kg}$ ) using a cuffed catheter Swan-Ganz for lung isolation and lavage, while the other lung was ventilated through a bronchoscope.

Liquid ventilation was also used for WLL, but without success in pediatric patients who did not tolerate the procedure ${ }^{12}$

In this study the WLLwas chosen through sequential lobar fiberoptic bronchoscopy with the patient under general anesthesia on spontaneous ventilation. The fiber bronchoscope was introduced adjacent to the tracheal tube with cuff and worked as a shutter lobe, which allowed the isolated lavage of each lung lobe minimizing the effects on the ventilation/perfusion ratio inherent to the procedure and allowing adequate gas exchange in the rest of the lung parenchyma.

The patient was kept under spontaneous ventilation, as the bronchoscope introduction adjacent to the tracheal tube in the presence of positive pressure ventilation caused major leak, limiting the usage of controlled mechanical ventilation.

\section{CONCLUSION}

This technique proved to be very safe and simple compared to others described in literature with no significant increase in cost compared to a diagnostic bronchoscopy. It also provided good hemodynamic and respiratory stability throughout the procedure and was considered safe and effective for pediatric population. 


\section{REFERÊNCIAS/REFERENCES}

1. Rosen SH, Castleman B, Liebow AA - Pulmonary alveolar proteinosis. N Engl J Med, 1958;258:1123-1142.

2. Ben-Dov I, Kishinevski Y, Roznman J et al. - Pulmonary alveolar proteinosis in Israel: ethnic clustering. Isr Med Assoc J, 1999;1:75-78.

3. Seymour JF, Presneill JJ - Pulmonary alveolar proteinosis: progress in the first 44 years. Am J Respir Crit Care Med, 2002;166:215-235.

4. Trapnell BC, Whitsett JA, Nakata K - Mechanisms of disease: pulmonary alveolar proteinosis. N Engl J Med, 2003;349:2527-2539.

5. Ramirez-Rivera J, Schultz RB, Dutton RE - Pulmonary alveolar proteinosis: a new technique and rationale for treatment. Arch Intern Med, 1963;112:419-431.

6. Ramirez-Rivera J, Kieffer RF Jr, Ball WC Jr - Bronchopulmonary lavage in man. Ann Intern Med, 1965;63(5):819-828.

7. Lippmann M, Mok MS, Wasserman $\mathrm{K}$ - Anaesthetic management for children with alveolar proteinosis using extracorporeal circulation. Report of two cases. Br J Anaesth, 1977; 49:173-177.

8. Mahut B, de Blic J, Le Bourgeois $\mathrm{M}$ et al. - Partial and massive lung lavages in an infant with severe pulmonary alveolar proteinosis. Pediatr Pulmonol, 1992;13:50-53.

9. Moazam F, Schmidt JH, Chesrown SE et al. - Total lung lavage for pulmonary alveolar proteinosis in an infant without the use of cardiopulmonary bypass. J Pediatr Surg, 1985;20:398-401.

10. Paschen $\mathrm{C}$, Reiter $\mathrm{K}$, Stanzel $\mathrm{F}$ et al. - Therapeutic lung lavages in children and adults. Respir Res, 2005;6:138.

11. McKenzie B, Wood RE, Bailey A - Airway management for unilateral lung lavage in children. Anesthesiology, 1989;70:550-553.

12. Tsai WC, Lewis $D$, Nasr SZ et al. - Liquid ventilation in an infant with pulmonary alveolar proteinosis. Pediatr Pulmonol, 1998;26:283-286.

13. Shah PL, Hansell D, Lawson PR et al. - Pulmonary alveolar proteinosis: clinical aspects and current concepts on pathogenesis. Thorax, 2000;55(1):67-77.

14. Luisetti M, Pochetti P, Rodi G et al. - Patients with pulmonary alveolar proteinosis enrolled in the San Matteo Hospital program for whole lung lavage: baseline characteristics and follow-up. Chest, 2001;120(4 Suppl):270S.

15. Kavuru MS, Popovich $M-$ Therapeutic whole lung lavage: a stop-gap therapy for alveolar proteinosis. Chest, 2002;122(4):1123-1124.
16. Wang BM, Stern EJ, Schmidt RA et al. - Diagnosing pulmonary alveolar proteinosis. A review and an update. Chest, 1997;111(2):460-466.

17. Morgan $\mathrm{C}-$ The benefits of whole lung lavage in pulmonary alveolar proteinosis. Eur Respir J, 2004;23(4):503-505.

18. Beccaria M, Luisetti M, Rodi G et al. - Long-term durable benefit after whole lung lavage in pulmonary alveolar proteinosis. Eur Respir J, 2004;23:526-531.

19. Stocche RM, Garcia LV, Klamt JG - Anestesia para lavagem pulmonar em paciente portador de proteinose alveolar pulmonar. Relato de caso. Rev Bras Anestesiol, 2000;50:4: 302-305.

20. Benumof $\mathrm{JL}-$ Anesthesia for Thoracic Surgery, $2^{\mathrm{a}} \mathrm{Ed}$, Philadelphia, WB Saunders, 1995;553.

21. Hurrion EM, Pearson GA, Firmin RK - Childhood pulmonary alveolar proteinosis: Extracorporeal membrane oxygenation with total cardiopulmonary support during bronchopulmonary lavage. Chest, 1994;106;638-640.

22. Hodges O, Zar HJ, Mamathuba R et al. - Bilateral partial lung lavage in an infant with pulmonary alveolar proteinosis. $\mathrm{Br} \mathrm{J}$ Anaesth, 2010;104:228-230.

23. Paquet $\mathrm{C}$, Karsli $\mathrm{C}-$ Technique of lung isolation for whole lung lavage in a child with pulmonary alveolar proteinosis. Anesthesiology, 2009;110:190-192.

24. Sivitanidis E, Tosson R, Wiebalck A et al. - Combination of extracorporeal membrane oxygenation (ECMO) and pulmonary lavage in a patient with pulmonary alveolar proteinosis. Eur J Cardiothorac Surg, 1999;15:370-372. 